\title{
Flow Characteristics Due To Bridge Piers With Sloped U/S Noses.
} m.m Elfiky, G.M Abdel-Aal, A.I EI-Terzy

\begin{abstract}
Discharge coefficient and energy losses due to bridge piers with upstream sloped noses have been investigated for open channels of different bed slopes under different flow conditions. In the theoretical study, the dimensional analysis, the energy equation and the continuity equation were employed. The analysis of the experimental data led to practical recommendations and charts applicable for the design of bridge waterways have been developed. improving the flow characteristics. The study comprises a theoretical approach to the problem and experimental investigations of the significance of the flow parameters on the phenomena under consideration
\end{abstract}

